\title{
Co-writing the Lives of Registered Nurses Employed under the Nurse Deployment Program of the Department of Health
}

\author{
Jay C. Barrios Jr., RN一 \\ jayconsignadobarriosjr@gmail.com \\ Staff Nurse, Calamba Medical Center, Inc., Brgy. Real, Calamba City, 4027, Philippines \\ Graduate Student, San Pablo Colleges, Hermanos Belen Street, San Pablo City, 4000, Philippines
}

\begin{abstract}
Community Health Nursing is one of the major areas in the nursing profession, yet it is not given many highlights in some circumstances. This condition puts new emphasis on the need for more research about this field of nursing.

Consequently, this research study explored the lived experiences of registered nurses employed under the Nurse Deployment Program of the DOH. Furthermore, it involved seven qualified participants from the Rural Health Unit of Nagcarlan, Laguna.

The researcher used descriptive, cross-sectional qualitative research, particularly a phenomenological approach by Husserl.The process includes four steps: bracketing, intuiting, analyzing and describing. The researcher facilitated a face-to-face, semi-structured interview in which the process was audio recorded to garner subjective data accurately. Thus, the researcher prepared a written topic guide, which is a list of openended questions to be answered by the participants, also known as procedural questions. The statements of participants were transcribed into text and then categorized into different themes. On the validation of the study, the researcher used triangulation

Several themes were identified and fit into two factors: first are the intrinsic factors which include proper time and stress management, and career advancement and personal growth; while the others are the extrinsic factors which include fair workload and compensation, and resolution of issues related to working experiences.

Based on the findings, the researcher developed a thematic framework that shows that extrinsic and intrinsic factors contributed to the satisfaction of the participants with their job, and made them stay in their chosen field. Hence, this calls for another research study using a mixed-method that approaches specifically the sequential exploratory design.
\end{abstract}

Keywords: community health nursing; lived experiences; internal factors; external factors; phenomenology

\section{Introduction}

Community Health Nurses (CHN) or Public Health Nurses are nurses who choose to practice their expertise towards care to people in the community, and conduct a thorough assessment and gather data about their client's health in a specific community assigned by the authority. 
Subsequently, the Department of Health (DOH) launched the Nurse Deployment Program (NDP) in 2014 to replace the Registered Nurses for Health Enhancement and Local Services (RN HEALS). In this program, employed nurses are given six months in contract wherein they will assist the DOH in the implementation of various programs, such as the National Immunization Program, National Tuberculosis Control Program, and Family Planning Program. They also function as advocates, health educators, information disseminators and perform other functions that are anchored with the DOH.

As one of the major areas in the nursing profession, Community Health Nursing is not given significant consideration. The resulting occurrences emphasize the need for more analysis and exploration in this area of the field. This requires further study about the situations and lived experiences of nurses employed under the said program.

It is vital to have adequate research data about the community health nurses to know their lived experiences while serving the people in the community. It is also essential to have updated research about this area of nursing since it might spark the interest of those aspiring nurses who are looking for inspiration and other options for their future areas of specialization.

Consequently, the researcher decided to conduct this study to describe the lived experiences of Community Health Nurses working in the rural areas of the community and to gain insights into those nurses who chose to stay even though they are not secured in terms of keeping the job.

\section{Review of Related Literature and Studies}

Motivation is something that drives a person to perform tasks and improve some parts of themselves. Thus, Marquis and Huston (2017) discussed several philosophies regarding Motivational Theory. First was Abraham Maslow's hierarchy of needs (1970) which indicated that people are motivated to satisfy certain needs that range from basic survival to more complex needs, and that people seek a higher need after meeting the lower needs predominantly. Another theory that was discussed is the Operant Conditioning and Behavior Modification of B. F. Skinner (1973). It demonstrated that people could be conditioned to act in a certain behavior based on a consistent punishment or reward system. This means that people change their behaviors according to the reinforcement that they may receive.

The belief of Frederick Herzberg (1987) that employees can be motivated by the work itself and that there is an internal or personal need to meet organizational goals was also highlighted on the motivationhygiene theory or two-factor theory. He also believed that it is possible to separate personal motivators such as recognition, advancement, and achievement from maintenance factors such as salary, job security, and interpersonal relationships and peers.

Consequently, either or intrinsic and extrinsic motivation takes part in the improvement of such behavior. The above literature explained the motivators that notably affect the job satisfaction of workers.

On the aspect of professional development, Huston (2017) stated that some nurses tend to develop high levels of competence in specific areas of nursing practice as a result of work experience and specialization, at the expense of staying mediocre in other areas of practice. Therefore, nurses who decide to stay in a specific area become competent only in that particular area of nursing.

Meanwhile, time management is the process of using a significant amount of time effectively. Stone and Treloar (2015) suggested that the problem may not be the amount of time, but rather, the proper usage of time. With that, Homisak (2012) notes that most of the people with poor time management skills spend inordinate amounts of time burning the candle at both ends, blaming others for their inefficiencies, and getting others to work harder. Thus, tasks may not be accomplished accordingly. On the other hand, Florida (2011) stated that nurses tend to use techniques of stress management for them to be productive in their profession and be retained for longer periods in their careers. Nurses, who are capable of managing stress, can meet the needs of their patients regarding nursing care. 
job.

Thus, proper management of time and stress greatly affects the choice of an employee to stay on his

Hoffman \& Scott (2003) suggest that nurses may be more satisfied in their careers when autonomous practice environments, financial incentives, and recognition of their professional status are in place. In addition, Tomey (2009) mentioned that to get more people into the industry and to hold onto the excellent staff that they already have, there's a need to increase their compensation.

Further, Nawab and Bhatti (2011) note that compensation as a method of enhancing employee job satisfaction and commitment to the organization may be useful in harnessing the full potential of employees. Additionally, the study examines the contribution of financial and non-financial compensation toward overall organizational commitment, which they can easily implement and increase in order to maximize employee contribution.

On the aspect of shifts and workload, It was reported by Ball et. al (2015) that working longer shifts and overtime was significantly associated with poorer patient safety, lower quality care, and fewer unattended patients.He also notes that nurses who work long hours exhibit higher instances of burnout and may experience job dissatisfaction.In support of their finding, Ericksen (2016) suggests that sleep-deprived nurses and those working long hours three consecutive days in a row experience decreased reaction time and poor sleep. He also notes that nurses who work long hours exhibit higher instances of burnout and may experience job dissatisfaction.

On the other hand, Tao et. It has been suggested by al (2018) that job satisfaction is the strongest predictor of nurses' retention, and that their retention could be improved by improving their job satisfaction management.. This means that reinforcing nurses positively, it makes them more satisfied with their job. Therefore, turnovers of nurses can be significantly reduced.

It is claimed in the study, 'Employee Benefits Basics (2015)' that over time, benefits have moved from basic "fringe benefits" to comprehensive, balanced programs that balance the personal and professional lives of employees.

On the contrary, Cherry (2016) stated that rewards can increase motivation in some cases, but this is not always the case.This may also lead to decreased motivation. Though it can motivate an individual externally, the thing that matters to them is those motivations that come within.

The literature above indicated that being compensated and having a fair workload results in the retention of an employee.

\section{Methodology}

The researcher used a descriptive, cross-sectional, qualitative research design, specifically a descriptive phenomenology that was developed by Husserl in 1962. It primarily insists on a careful description of the ordinary conscious experience of an individual. According to Polit \& Beck (2012), a phenomenology is an approach to discovering the meaning of people's life experiences. This means that the researcher explored the lived experiences of the participants without having recourse to theories, deductions, or assumptions. Hence, the researcher avoided readings about the topic to avoid preconceptions because the interpretation of the phenomenon should be based on the participants' viewpoints rather than on any prior readings or information.

Descriptive phenomenology involves four steps including bracketing, intuiting, analyzing, and describing. Bracketing is the process in which the researcher holds or avoids preconceptions about the phenomenon that is being studied. Though bracketing can never be achieved fully, the researcher strives to bracket out any presuppositions to interpret the data purely. Meanwhile, intuiting occurs when the researchers preserve openness to the meanings of the phenomenon as provided by the key informants who have experienced it. Analyzing is defined as the extraction of the significant statements and creation of categories to make sense of the essential meaning of their lived experiences while describing is the process of 
understanding and giving the meaning of the phenomenon.

A technique that was used to gather data needed for this study is a face-to-face, semi-structured interview. The researcher prepared a written topic guide, which is a list of open-ended questions to be answered by the participants, also known as procedural questions. Most of the questions were asked, while some were added depending on the need of the researcher to ask further. This technique provided the researcher flexibility in terms of data gathering since the questions alone led participants to narrate more. This also increased cogency since it provided the opportunity for the researcher to clarify things that were stated.

The statements of participants were transcribed into text and then categorized into different themes. The language used by the participants was in Filipino and English. Thus, the researcher did not translate those statements into pure English text to preserve the authenticity of the data.

On the validation of the study, the researcher used triangulation. Based on Creswell \& Poth (2015), it is one of the four types of re-conceptualization of validation in which the researcher conforms from several resources as having multiple data sources, methods, and theoretical schemes; or having the interpretations reviewed and corrected by the participants. It was seconded by Polit \& Beck (2012) as they define it as the use of multiple methods to collect and interpret data regarding the lived experiences. It was used to converge on an accurate representation of the phenomenon. Then, the researcher proceeded to write a literature review to support his analysis.

\section{Results and Discussion}

Based on the subjective data from the participants that were interpreted by the researcher, their experiences both either positive or negative made them stay in their chosen field. Two major factors were identified: the intrinsic and extrinsic factors. Intrinsic factors include personal growth, professional and career advancement, and enhanced ability to manage stress and time properly; while extrinsic factors include fair workload and compensation, and resolution of issues related to working experiences.

On the intrinsic factors, personal growth was included. Nurses were able to develop their interpersonal relationships since they were exposed to people of different colors and temperatures. In terms of professional and career advancement, nurses were able to develop and enhance their skills in assessing patients, administering vaccines, diagnosing simple diseases, and formulating care plans. Their knowledge of various programs of the $\mathrm{DOH}$ was also hastened. Development on their ability to manage stress and their time were significantly improved. They were able to finish their tasks despite their time-consuming activities.

On the extrinsic factors per se, nurses were compensated well. They were able to receive adequate amounts of salary and were given fair workloads since the population of their areas was equally divided. They were also given privileges to experience holidays. Most importantly, they were also able to resolve issues regarding work-related experiences. Whenever they encountered such conflicts, they acted professionally and dealt with clients with humility. If a problem arose, they immediately reported things to their supervisor.

\section{Conclusion}

The study was made to explore the lived experiences of community health nurses; thus, the researcher was able to extract significant themes about those experiences from the subjective data that was provided by the participants. Based on the findings, the researcher had developed a thematic framework that shows that the extrinsic and intrinsic factors contributed to participants' satisfaction with their job and made them stay in their chosen field. 


\section{References}

Ball, J., Dall'Ora, C., \& Griffiths, P. (2015). The 12-hour Shift: Friend or Foe? Nursing

Times, 111(6), 12-14. Retrieved from: http://www.nursingtimes.net/clinical-archive/patient-safety/the-12-hourshift-friend-or-foe/5081694.fullarticle

Cherry, K. (2016). What are extrinsic motivation and rewards? Retrieved ～from: ～http://www.verywell.com/what-is-extrinsicmotication-2795164

Creswell, J. \& Poth, C. (2017). Qualitative Inquiry \& Research Design: $\quad$ Choosing Among Five Approaches (4 ${ }^{\text {th }}$ Edition). New Delhi: Sage Publications.

Ericksen, K. (2016). Nursing debate: 8-Hhour shifts vs. 12-Hours shift. Retrieved from:http://www.rasmussen.edu/degrees/nursing/blog/nursing-debate-8- hour-shifts-vs-12-hour-shifts/

Florida, L. (2011). Stress Management: Its Implication on the Productivity of the Staff Nurses at United Candelaria Doctors Hospital, Candelaria Quezon.

Hoffman, A., \& Scott, L. (2003). Role Stress and Career Satisfaction Among Registered Nurses by Work Shift Patterns. The Journal of NursingAdministration: June 2003 - Volume 33 - Issue 6 - p 337-342

Homisak, L. (2012). Time and Efficiency Redux: How do you take better control of your time? Podiatry Management, 31(3), 41-44.

Mason, J. (2018). Qualitative Researching (3 ${ }^{\text {rd }}$ Edition). London: Sage Publications Inc.

Marquis, B., \& Huston, C. (2017). Leadership Roles and Management Functions in Nursing: Theory and Application (9 $9^{\text {th }}$ Edition). Philadelphia: Wolters Kluwer Health. Chapters 9, 11, 17, 18, and 21.

McLeod, S. (2015). Skinner - Operant Conditioning. Retrieved from: http://www.simplypsychology.org/operant-

conditioning.html

Nawab S., \& Bhatti, K. (2011). Influence of Employee Compensation on Organizational Commitment and Job Satisfaction: A Case

Study of Educational Sector of Pakistan. International Journal of Business and Social Science Vol. 2 No. 8; May 2011

Polit, D., \& Beck, C. (2012). Nursing Research: Generating and Assessing $\quad$ Evidence for Nursing Practice (9 $9^{\text {th }}$ Edition). Philadelphia: Wolters Kluwer Health/ Lippincott Williams \& Wilkins. Chapters 4, 5, 20, 21, 22, 23, and 24.

Stone, T. \& Treloar, A. (2015). "How did it get so late so soon?": Tips and Tricks for managing time. Nursing \& Health Sciences. 17(4), 409-411. Doi:10.1111/nhs.12208

Tao, L., Guo, H., Liu, S., \& Li, J. (2018). Work Stress and Job Satisfaction of Community Health Nurses in Southwest China. Biomedical Research 2018; 29 (3): 510-518

Tomey, A. M. (2009). Guide to Nursing Management and Leadership ( $8^{\text {th }}$ Edition). St. Louis, Mo.: Mosby Elsevier

Timzi, M., Malik, M., \& Hasan, M. (2007). Measuring Satisfaction: Investigation regarding Age, Tenure and Job Satisfaction of White-collar Employees. Retrieved from: google.com/site/icbmbangkok2/3.Muhammad.Ali.Timzi 